\begin{tabular}{|c|}
\hline $\begin{array}{l}\underline{\underline{\underline{\underline{I I I}}}} \\
\\
\text { DESENVOLVIMENTO } \\
\text { E MEIO AMBIENTE }\end{array}$ \\
\hline
\end{tabular}

\title{
As estratégias de enfrentamento das mudanças climáticas expressas nas políticas públicas federais do Brasil
}

\section{Climate Change Coping Strategy Expressed in the Federal Public Policies in Brazil}

\author{
Frederico Monteiro NEVES ${ }^{1 *}$, Manyu $\mathrm{CHANG}^{2}$, Naína PIERRI ${ }^{3}$ \\ ${ }^{1}$ Departamento de Meio Ambiente, Centrais Elétricas Brasileiras S.A. (Eletrobras), Rio de Janeiro, RJ, Brasil. \\ ${ }^{2}$ Centro de Pesquisas René Rachou (CPqRR), Fundação Oswaldo Cruz (FIOCRUZ), Belo Horizonte, MG, Brasil. \\ ${ }^{3}$ Programa de Pós-Graduação em Meio Ambiente e Desenvolvimento (PPGMADE), Universidade Federal do Paraná (UFPR), Curitiba, PR, Brasil. \\ *E-mail de contato: fmonteironeves@yahoo.com.br
}

Artigo recebido em 8 de setembro de 2014, versão final aceita em 11 de junho de 2015.

RESUMO O objetivo deste artigo é analisar a estratégia de enfrentamento das mudanças climáticas no Brasil expressas nas políticas públicas do governo federal até 2012, buscando identificar a concepção implícita de desenvolvimento à luz do objetivo geral da sustentabilidade. Além da Política Nacional sobre Mudança do Clima (PNMC), foram analisados os planos de desenvolvimento dos seguintes setores: controle do desmatamento, energia, agropecuária e transporte. A metodologia teve como base a análise de conteúdo de documentos oficiais, sendo sua interpretação apoiada em pesquisa bibliográfica e nas informações obtidas em entrevistas abertas com informantes qualificados. Os resultados mostram que a PNMC privilegia ações de mitigação em detrimento daquelas voltadas à adaptação. As contradições dessa estratégia ficam aparentes em temas como exploração do pré-sal, priorização de investimentos na agropecuária de grande escala e a não consideração da desigualdade social. A conclusão indica que essa estratégia governamental segue a reboque do objetivo principal de fomentar um modelo de desenvolvimento ancorado no crescimento econômico.

Palavras-chave: sustentabilidade; mudanças climáticas; política ambiental; desmatamento; energia.

ABSTRACT The objective of this paper is to analyze the climate change coping strategy in Brazil expressed in the federal government policy up to 2012, seeking to identify the implicit concept of development in light of the overall goal of sustainability. Besides the National Policy on Climate Change (NPCC), the development plans of the following sectors were also analyzed: combat to deforestation, energy, agriculture and transport. The methodology was based on content analysis of the official documents, which was supported by literature review and information obtained in interviews with qualified informants. The results showed that the NPCC favors mitigation actions over those directed to adaptation. The contradictions of this strategy become apparent in areas such as the sub-salt exploration, investment in large-scale farming, and no consideration of social inequality. The conclusion indicates that the consideration of climate change issues by the government is secondary, being the main objective to promote a development model anchored on economic growth.

Keywords: sustainability; climate change; environmental policy; deforestation; energy. 


\section{Introdução}

O enfrentamento da questão climática configura-se em um dos grandes desafios científicos e políticos deste século (Giddens, 2010). Remete à percepção de que os limites ecossistêmicos regionais e mesmo planetários estariam sendo ultrapassados pelas sociedades modernas ao utilizar cada vez mais intensamente recursos naturais limitados e pela contínua degradação socioambiental, que se manifesta, entre outros, nas emissões de gases de efeito estufa (GEE) e nas vulnerabilidades sociais e ambientais (Vitousek et al., 1997; IPCC, 2012; UNEP, 2012).

O equacionamento das mudanças climáticas projeta, em última instância, uma crítica aos padrões insustentáveis do modelo dominante de desenvolvimento das sociedades capitalistas e seus modos de vida. A perspectiva da sustentabilidade, alternativamente, surge como um possível caminho para construir novas formas de produção e consumo e, com isso, de equacionamento das causas e efeitos da mudança do clima. Nessa abordagem, as dimensões ecológica, social e econômica do desenvolvimento seriam contempladas, reforçando-se o caráter de mediação da dimensão econômica, que não poderia ser um fim em si mesmo, senão condição de realização das dimensões ecológica e social (entendida em sua acepção mais ampla) (Leff, 2006; Sachs, 2008).

No Brasil, há um movimento governamental recente de introdução da mudança climática nas políticas ambientais nacionais, a qual tem sido colocada, principalmente após 2009, ano em que a política nacional sobre mudança do clima foi sancionada, como uma agenda do Estado (Romeiro \& Parente, 2011). Essa política, diferentemente de outras políticas ambientais mais específicas, e em razão das peculiaridades da questão climática, aborda temas tão diversos quanto desmatamento, energia, agropecuária, siderurgia, geração de emprego e renda, entre outros, o que mostra nitidamente a imbricação dos temas mudanças climáticas e desenvolvimento. Essa característica faz da política climática um objeto analítico privilegiado para compreender como os últimos governos nacionais têm tratado a relação desenvolvimento e meio ambiente.

Nesse sentido, este artigo busca contribuir para esse debate a partir das discussões sobre a mudança do clima e sua relação com o desenvolvimento atual do Brasil, enfatizando as características de tal desenvolvimento que corroboram para o agravamento ou a atenuação desse problema ambiental. São analisadas, assim, tanto as políticas ambientais específicas relativas à mudança do clima como também as políticas de desenvolvimento que se referem a problemas, setores ou atividades de forte incidência nessa problemática, a saber: desmatamento, energia, agropecuária e transportes.

\section{Abordagem metodológica}

A política governamental para a mudança do clima conforma-se tanto nas políticas ambientais específicas como também nas políticas de desenvolvimento, as quais podem ter consequências negativas ou positivas sobre a mitigação e a adaptação.

Com base no objetivo traçado, os seguintes instrumentos de políticas públicas foram analisados: a Lei n. 12.187, de 29 de dezembro de 2009, que institui a Política Nacional sobre Mudança do Clima (PNMC); o Decreto n. 7.390, de 9 de dezembro de 2010, que regulamenta os artigos $6^{\circ}, 11^{\circ}$ e $12^{\circ}$ da $\mathrm{PNMC}^{1}$; e os planos setoriais de clima elaborados até 2012, que impactam diretamente sobre a meta de redução das emissões de GEE do Brasil, quais sejam: o Plano de Ação para a Prevenção e Controle do Desmatamento na Amazônia Legal (PPCDAm), o Plano de Ação para a Prevenção e Controle do Desmatamento e das Queimadas no Cerrado (PPCerrado), o Plano para a Consolidação de uma Economia de Baixa Emissão de Carbono na Agricultura (ABC), o Plano Decenal de Energia 2020 (PDE) e o Fundo Nacional sobre Mudança do Clima. Também são analisados os seguintes planos de desenvolvimento: Plano Agrícola e Pecuário 2011-2012 (PAP); Plano Nacional de Logística

${ }^{1}$ O Art. $6^{\circ}$ aborda os instrumentos da Política Nacional sobre Mudança do Clima; o Art. $11^{\circ}$ aborda os planos setoriais de clima; e o Art. $12^{\circ}$, as ações de mitigação a serem estabelecidas. 
e Transportes (PNLT); Plano Nacional de Energia 2030 (PNE) e as alterações feitas no Código Florestal. Esta última, apesar de ser uma política ambiental, foi objeto de alterações recentes fomentadas por setores rurais desenvolvimentistas do país.

Além desses planos setoriais de clima, há outros planos que foram concluídos em 2013 e que não estão contemplados nessa análise, a saber: o Plano de Mineração de Baixa Emissão de Carbono, o Plano Setorial de Transporte e de Mobilidade Urbana para Mitigação da Mudança do Clima e o Plano Setorial da Saúde para Mitigação e Adaptação à Mudança do Clima, bem como os planos setoriais em fase de elaboração, como o Plano de redução de emissões da Siderurgia e o Plano Nacional de Adaptação, que deverão ser concluídos em 2015.

Ressalta-se que, ainda que nem todos os planos setoriais de clima sejam contemplados neste artigo, os planos analisados se referem aos principais setores que têm maior repercussão sobre a questão climática no Brasil; sendo assim, oferecem indícios significativos da forma como o governo federal busca tratar esse tema. Ademais, este artigo se limitou a analisar as iniciativas em âmbito federal, embora, atualmente, haja diversas iniciativas em outros níveis da federação, nos estados e municípios (a exemplo das políticas de clima das cidades de São Paulo e Rio de Janeiro), cabendo a outras pesquisas averiguá-las.

Para efeitos deste estudo, consideraram-se as ações propostas nos instrumentos de política pública aludidos como indicadores da forma pela qual o governo federal se propõe a tratar os temas relacionados à mudança do clima, independentemente do que se possa constatar ou especular em relação a sua aplicação atual ou futura.

A partir das discussões sobre a sustentabilidade e suas dimensões (Pierri, 2001; Leff, 2006), foi elaborada uma matriz com seis aspectos qualitativos (Tabela 1) para a realização da análise de conteúdo dos documentos que instituem as políticas e planos, quais sejam: (1) impacto sobre as emissões de gases de efeito estufa (GEE); (2) impacto sobre a conservação de florestas; (3) impacto sobre a geração de emprego e renda; (4) impacto sobre a desigualdade social; (5) impacto sobre a adaptação; e (6) impacto sobre o crescimento econômico do país.

Para cada um desses aspectos foi definida uma escala de variação quantitativa de $(-1)$ a $(+2)$ a fim de facilitar a comparação das diferentes políticas e a apreciação do conjunto. Assim, foram definidas quatro notas a serem atribuídas a partir da análise qualitativa de diversos elementos com os seguintes significados: (-1) impacto negativo sobre determinado aspecto (e.g. aumento das emissões de GEE ou do desmatamento); (0) impacto não definido na política; (1) intenção genérica (e.g. determinado plano busca a adaptação como um dos objetivos, mas não define os instrumentos ou prazos); e (2) impacto positivo sobre determinado aspecto (e.g. redução das emissões de GEE ou do desmatamento, ou aumento da geração de emprego ou redução da desigualdade social) (Tabela 1). 
TABELA 1 - Matriz de aspectos para a análise das políticas públicas.

\begin{tabular}{|c|c|c|}
\hline Aspecto & Descrição & Escala de variação \\
\hline \multirow{4}{*}{ 1. Emissões de GEE } & \multirow{4}{*}{$\begin{array}{l}\text { Redução ou aumento } \\
\text { de emissões de GEE }\end{array}$} & -1 Aumento de emissões \\
\hline & & Não propõe \\
\hline & & 1 Intenção genérica de redução de emissões \\
\hline & & 2 Proposta de redução de emissões com valores e prazos definidos \\
\hline \multirow{4}{*}{$\begin{array}{l}\text { 2. Conservação } \\
\text { de florestas }\end{array}$} & \multirow{4}{*}{$\begin{array}{l}\text { Estímulo/desestímulo } \\
\text { a conservação de } \\
\text { florestas }\end{array}$} & -1 Aumento da degradação \\
\hline & & 0 Não definido \\
\hline & & 1 Intenção genérica da conservação \\
\hline & & $\begin{array}{l}2 \text { Proposta de redução do desmatamento com valores e prazos defi- } \\
\text { nidos }\end{array}$ \\
\hline \multirow{4}{*}{$\begin{array}{l}\text { 3. Geração de } \\
\text { emprego e renda }\end{array}$} & \multirow{4}{*}{$\begin{array}{c}\text { Fomento a geração de } \\
\text { emprego e renda }\end{array}$} & -1 Diminuição do emprego e renda \\
\hline & & 0 Não definido \\
\hline & & 1 Intenção genérica de aumento \\
\hline & & 2 Proposta de aumento de emprego e renda definida \\
\hline \multirow{4}{*}{$\begin{array}{l}\text { 4. Desigualdade } \\
\text { Social }\end{array}$} & \multirow{4}{*}{$\begin{array}{l}\text { Nível de impacto das } \\
\text { ações em relação à } \\
\text { desigualdade social }\end{array}$} & -1 Aumento da desigualdade \\
\hline & & Não definido \\
\hline & & 1 Intenção genérica de diminuição da desigualdade \\
\hline & & 2 Proposta de diminuição da desigualdade \\
\hline \multirow{4}{*}{ 5. Adaptação } & \multirow{4}{*}{$\begin{array}{l}\text { Ações que contribuem } \\
\text { para aumentar ou } \\
\text { diminuir a adaptação } \\
\text { (adaptação social, tec- } \\
\text { nológica entre outras) }\end{array}$} & -1 Diminuição da capacidade de adaptação \\
\hline & & 0 Não definido \\
\hline & & 1 Intenção de adaptação genérica \\
\hline & & 2 Proposta de adaptação definida \\
\hline \multirow{4}{*}{$\begin{array}{l}\text { 6. Crescimento } \\
\text { econômico }\end{array}$} & \multirow{4}{*}{$\begin{array}{l}\text { Ações que fomentam ou } \\
\text { inibem o crescimento } \\
\text { econômico }\end{array}$} & -1 Ações desestimuladoras do crescimento econômico \\
\hline & & 0 Não definido \\
\hline & & 1 Intenção genérica de estímulo ao crescimento econômico \\
\hline & & 2 Estímulo ao crescimento econômico como ação prioritária \\
\hline
\end{tabular}


A avaliação desses aspectos serviu de guia para verificar a contribuição das ações propostas nas políticas públicas para mitigação e adaptação, assim como para identificar a relação entre crescimento econômico e contribuições nos aspectos sociais e ambientais presentes em cada um. Tal avaliação também facilitou caracterizar, dentro do conjunto da política de clima do país, as dimensões da sustentabilidade (econômica, ecológica e social) que são privilegiadas, sendo que os aspectos 1 e 2 são mais relacionados à dimensão ecológica; os aspectos 3 e 4, à dimensão social; o aspecto 5, a todas as dimensões; e o aspecto 6, à dimensão econômica.

Os subsídios para tal análise partiram de ampla pesquisa bibliográfica, participação em eventos científicos especializados e realização de entrevistas abertas com informantes qualificados envolvidos diretamente com as temáticas específicas, incluindo gestores públicos de alto nível de governos federal, estaduais e municipais, pesquisadores e ambientalistas.

Nas seções 3 e 4 é feita uma breve descrição das políticas públicas analisadas e seus instrumentos de gestão, indicando os pontos mais relevantes para a discussão que será realizada na seção 5 .

\section{A Política Nacional sobre Mudança do Clima e seus instrumentos}

A PNMC foi sancionada em dezembro de 2009, logo após a realização da $15^{\mathrm{a}}$ Conferência das Partes da Convenção do Clima da ONU (COP 15), em Copenhague, concretizando a definição de metas voluntárias e instrumentos para a redução de emissões de GEE pelo governo brasileiro. Nela estão expressas, mesmo que de forma geral, as linhas de ação para os próximos anos, podendo ser considerada uma "política-quadro" no país para o tratamento do tema.

Dentre seus objetivos destacam-se três grandes diretrizes estabelecidas pelo governo: redução de emissões de GEE e aumento das remoções por sumidouros; preservação, conservação e recuperação dos recursos ambientais, com ênfase em iniciativas de redução do desmatamento e reflorestamento, que até 2010 se colocava como o principal desafio do governo brasileiro para diminuir as emissões de GEE; e estabelecimento de medidas de adaptação pelas três esferas da federação (Brasil, 2009).

Em relação a seus pressupostos, está expresso no texto da lei que essa política se pauta nos princípios da precaução, da prevenção, da participação cidadã, do desenvolvimento sustentável e das responsabilidades comuns, porém diferenciadas em âmbito internacional. Além disso, define que seus objetivos deverão estar em consonância com o desenvolvimento sustentável a fim de buscar o crescimento econômico, a erradicação da pobreza e a redução das desigualdades sociais (Brasil, 2009).

Para a consecução de seus objetivos, a PNMC estabelece que planos setoriais de mitigação deverão internalizar a meta voluntária de redução de emissões de GEE, de acordo com as peculiaridades de cada setor. Essa meta define uma redução entre $36,1 \%$ e $38,9 \%$ dessas emissões projetadas para o país até 2020 , considerando que a expansão da economia tenha um crescimento anual projetado de cerca de $5 \%$, sem ações de mitigação (cenário business as usual) (Brasil, 2009).

O Decreto n. 7.390 projeta para 2020 a emissão total de GEE para o país de cerca de 3.236 milhões $\mathrm{tCO}_{2}$ eq ${ }^{2}$. Tal projeção é a soma das projeções de emissões dos seguintes setores: "mudança de uso da terra", "energia", "agropecuária e processos industriais" e "tratamento de resíduos" (Brasil, 2010).

A meta de mitigação da PNMC (36,1\% e 38,9\%) deverá incidir sobre essa projeção de emissão total do país. Assim, o volume de redução de emissão que corresponde ao percentual definido compreende entre 1.168 milhões de $\mathrm{tCO}_{2}$ eq e 1.259 milhões de $\mathrm{tCO}_{2}$ eq. Para atingir essa meta, são propostas ações dentro dos distintos planos de clima, cujo detalhamento está na Tabela 2.

\footnotetext{
${ }^{2}$ Tonelada de dióxido de carbono equivalente.
} 
TABELA 2 - Planos setoriais de clima e as ações propostas para reduzir as emissões de GEE do país até 2020.

\section{Plano setorial}

Plano de Ação para a Prevenção

e Controle do Desmatamento na

Amazônia Legal (PPCDAm)

Plano de Ação para a Prevenção e

Controle do Desmatamento e das

Queimadas no Cerrado (PPCerrado)
Ação

Redução de $80 \%$ dos índices anuais de desmatamento na Amazônia Legal em relação à média verificada entre os anos 1996 e 2005.

Redução de 40\% dos índices anuais de desmatamento no Bioma Cerrado em relação à média verificada entre os anos 1999 e 2008.

Recuperação de 15 milhões de hectares de pastagens degradadas.

Ampliação do sistema de integração lavoura-pecuária-floresta em 4 milhões de hectares.

Plano Setorial de Mitigação e de Adaptação às Mudanças Climáticas Visando à Consolidação de uma Economia de Baixa Emissão de Carbono na Agricultura (Plano ABC)

Expansão da prática de plantio direto na palha em 8 milhões de hectares.

Expansão da fixação biológica de nitrogênio em 5,5 milhões de hectares de áreas de cultivo, em substituição ao uso de fertilizantes nitrogenados.

Expansão do plantio de florestas em 3 milhões de hectares.

Ampliação do uso de tecnologias para tratamento de 4,4 milhões de $\mathrm{m}^{3}$ de dejetos de animais.

Expansão da oferta hidroelétrica, da oferta de fontes alternativas renováveis (centrais Plano Decenal de Energia (PDE) eólicas, pequenas centrais hidroelétricas e bioeletricidade), da oferta de biocombustíveis, e incremento da eficiência energética.

FONTE: Brasil (2010).

APNMC e os planos setoriais contemplam tanto instrumentos de gestão ambiental do tipo comando e controle quanto de mercado para operacionalizar as ações propostas. Assim, pode-se verificar a definição de dois grandes instrumentos de gestão que pautam as ações presentes nos planos setoriais: a definição de metas de emissão de GEE até 2020 (comando e controle), que é a base para as ações contempladas nos planos setoriais; e a indicação da criação do Mercado Brasileiro de Redução de Emissão (MBRE), que está longe de ser efetivado, mas já recebe amparo nessa lei. A Tabela 3 discrimina os principais instrumentos de gestão de cada plano setorial de clima segundo tal classificação. 
TABELA 3 - Principais instrumentos de gestão ambiental utilizados pelo governo federal para operacionalizar as ações propostas na PNMC.

\begin{tabular}{|c|c|c|}
\hline Políticas climáticas & Instrumentos de comando e controle & Instrumentos de mercado \\
\hline $\begin{array}{l}\text { Política Nacional sobre } \\
\text { Mudança do clima }\end{array}$ & $\begin{array}{l}\text { Metas de redução de emissão de GEE projetadas } \\
\text { para } 2020 .\end{array}$ & $\begin{array}{l}\text { MBRE - Mercado brasileiro de redução } \\
\text { de emissão. }\end{array}$ \\
\hline \multirow[b]{2}{*}{ PPCDAm } & Criação de Unidades de Conservação. & $\begin{array}{l}\text { Licitação Pública de Concessão Florestal no } \\
\text { estado de Roraima. }\end{array}$ \\
\hline & $\begin{array}{l}\text { Fiscalização do Ibama e aplicação de multas em } \\
\text { áreas de desmatamento ilegal. } \\
\text { Regularização fundiária de posseiros na Amazônia } \\
\text { Legal por meio do Programa Amazônia Terra Legal } \\
\text { do Ministério do Desenvolvimento Agrário (MDA). }\end{array}$ & $\begin{array}{l}\text { Subvenção direta ao produtor extrativista } \\
\text { para garantir preços mínimos para os prin- } \\
\text { cipais produtos da floresta (subsídio). }\end{array}$ \\
\hline \multirow{5}{*}{ PPCerrado } & $\begin{array}{l}\text { Prevenção e o controle das queimadas e incên- } \\
\text { dios florestais. }\end{array}$ & $\begin{array}{l}\text { Fomento ao manejo florestal de espécies na- } \\
\text { tivas e ampliação do plantio de florestas para } \\
\text { fins produtivos (financiamento). }\end{array}$ \\
\hline & $\begin{array}{l}\text { Homologar } 300 \text { mil hectares de terras indígenas e } \\
\text { demarcar outros 5,5 milhões hectares. }\end{array}$ & $\begin{array}{l}\text { Criação de incentivos econômicos e de } \\
\text { crédito que promovam a recuperação das } \\
\text { Áreas de Preservação Permanente e de Re- } \\
\text { serva Legal, inclusive por meio do MDL. }\end{array}$ \\
\hline & $\begin{array}{l}\text { Ampliação e qualificação da assistência técnica e ex- } \\
\text { tensão rural em modelos de produção sustentáveis. }\end{array}$ & $\begin{array}{l}\text { Ampliar os Fundos Constitucionais (FCO, } \\
\text { FNE e FNO) para financiar projetos de re- } \\
\text { florestamento para siderurgia e de manejo } \\
\text { florestal e sistemas agroflorestais no Cerra- } \\
\text { do (Ministério da Integração Nacional). }\end{array}$ \\
\hline & $\begin{array}{l}\text { Fiscalização nas rodovias e entroncamentos } \\
\text { (IBAMA, PRF). }\end{array}$ & $\begin{array}{l}\text { Aumentar a efetividade do Protocolo Verde } \\
\text { pelos bancos públicos e privados (Ministé- } \\
\text { rio da Fazenda). }\end{array}$ \\
\hline & $\begin{array}{l}\text { Ampliar em 2,5 milhões de hectares as áreas de } \\
\text { Unidades de Conservação Federais (ICMBio). }\end{array}$ & $\begin{array}{l}\text { Incluir sete novos produtos da sociobiodi- } \\
\text { versidade na Política de Garantia de Preços } \\
\text { Mínimos (PGPM), do MMA }\end{array}$ \\
\hline
\end{tabular}




\begin{tabular}{|c|c|c|}
\hline Políticas climáticas & Instrumentos de comando e controle & Instrumentos de mercado \\
\hline & $\begin{array}{l}\text { Realizar o macrozoneamento ecológico econômi- } \\
\text { co do bioma e apoiar os estados em seus zonea- } \\
\text { mentos. }\end{array}$ & $\begin{array}{l}\text { Ampliar em } 3,2 \text { milhões de hectares a área } \\
\text { de floresta plantada para a siderurgia a car- } \\
\text { vão vegetal (MAPA e MDIC). }\end{array}$ \\
\hline & \multirow{3}{*}{$\begin{array}{l}\text { Disponibilizar assistência técnica e extensão ru- } \\
\text { ral (ATER) em manejo florestal do Cerrado nos } \\
\text { assentamentos do INCRA. }\end{array}$} & $\begin{array}{l}\text { Incluir produtos do agroextrativismo e da } \\
\text { sociobiodiversidade no Programa de Aqui- } \\
\text { sição de Alimentos (PAA) }\end{array}$ \\
\hline & & $\begin{array}{l}\text { Realizar o "Pronaf Sustentável" de forma } \\
\text { prioritária nos municípios do Cerrado (MDA). }\end{array}$ \\
\hline & & $\begin{array}{l}\text { Promoção do pagamento por serviços am- } \\
\text { bientais no bioma Cerrado, após aprovação } \\
\text { de projeto de lei específico para esse tema. }\end{array}$ \\
\hline \multirow{2}{*}{ Plano ABC } & & $\begin{array}{l}\text { Financiamento da agricultura familiar por } \\
\text { meio do Programa Nacional de Fortaleci- } \\
\text { mento da Agricultura Familiar (PRONAF). }\end{array}$ \\
\hline & & $\begin{array}{l}\text { Financiamento das práticas contempladas } \\
\text { nesse plano por meio dos bancos oficiais } \\
\text { (R } \$ 3,15 \text { bilhões de reais). }\end{array}$ \\
\hline \multirow{6}{*}{ PDE 2020} & \multirow{6}{*}{$\begin{array}{l}\text { Definição das quotas de adição de biodiesel no } \\
\text { diesel ao longo do tempo. }\end{array}$} & $\begin{array}{l}\text { Realização de leilões para exploração de pe- } \\
\text { tróleo, geração de energia elétrica, linhas de } \\
\text { transmissão, gás e outros energéticos. }\end{array}$ \\
\hline & & Expansão do Proinfa (subsídio). \\
\hline & & Continuidade do PROALCOOL (subsídio). \\
\hline & & $\begin{array}{l}\text { Programa Nacional de Produção e Uso de } \\
\text { Biodiesel (subsídio). }\end{array}$ \\
\hline & & Financiamentos públicos. \\
\hline & & Realização de leilões de energia renovável. \\
\hline Fundo Clima & $\begin{array}{l}26 \text { milhões de reais, não reembolsáveis, serão in- } \\
\text { vestidos em pesquisa, mobilização e avaliações } \\
\text { de impacto das mudanças do clima. }\end{array}$ & $\begin{array}{l}200 \text { milhões de reais para empréstimos vol- } \\
\text { tados para a área produtiva. }\end{array}$ \\
\hline
\end{tabular}

FONTE: Brasil (2009; 2010); EPE (2011). 


\section{Planos de desenvolvimento}

O Plano Agrícola e Pecuário (PAP) é o principal instrumento de planejamento do Ministério da Agricultura, Pecuária e Abastecimento (MAPA) do governo federal. Entre seus objetivos estão: expandir de 161,5 milhões para 169,5 milhões de toneladas a produção de grãos, fibras e oleaginosas em 2012; estimular o desenvolvimento sustentável da agropecuária, incentivando especialmente as práticas agronômicas que assegurem a mitigação dos gases causadores de efeito estufa; incentivar a recuperação de pastagens, fomentar o aumento da produtividade pecuária e renovação do plantel, como forma de aumentar a oferta de carne bovina; estimular a renovação e ampliação das áreas cultivadas com cana-de-açúcar; garantir o volume adequado de recursos do Sistema Nacional de Crédito Rural (SNCR), sobretudo a taxas controladas; e reforçar o apoio ao médio produtor rural (MAPA, 2011).

$\mathrm{O}$ PAP consolida diversas tendências em relação à agropecuária no Brasil, como o aumento do investimento para a agricultura empresarial, incluindo aquela destinada à exportação, o incentivo ao médio produtor rural, a manutenção da política de preços mínimos para determinados produtos nacionais, e o aumento dos recursos para a pecuária. Além disso, define uma série de iniciativas que visam à produção rural considerada mais sustentável, como o Programa ABC (Agricultura de Baixo Carbono).

O Plano Nacional de Logística e Transportes (PNLT) é desenvolvido pelo Ministério dos Transportes em cooperação com o Ministério da Defesa. Tem como objetivos formalizar instrumentos de análise para dar suporte ao planejamento de intervenções públicas e privadas na infraestrutura e na organização dos transportes. O total de investimentos previsto para todos os vetores logísticos e modais até 2023 é de cerca de 290,8 bilhões de reais. Desse total, propõe-se que cerca de $51 \%$ sejam destinados à ampliação ou melhoria do modal ferroviário; $24 \%$, para o modal rodoviário; cerca de $13 \%$, para portos; $5,4 \%$, para o modal hidroviário; e 4,5\%, para aeroportos (MT, 2009).

O Plano Nacional de Energia (PNE) é elaborado pela Empresa de Pesquisa Energética (EPE), fazendo parte do instrumental de planejamento do Ministério de Minas e Energia (MME). Busca orientar tendências e estratégias de expansão do setor em longo prazo (2030), enquanto o planejamento de médio prazo está no Plano Decenal de Energia (PDE 2020), um dos planos de clima da PNMC.

Em relação aos investimentos, no PNE é estimado que o montante necessário para a expansão do setor energético no período $2005-2030$ pode ultrapassar 800 bilhões de dólares, concentrando mais de $80 \%$ nos setores de petróleo e energia elétrica. Não há menção às energias consideradas alternativas, como eólica e solar, no montante de investimentos estimados. Entretanto o plano cita que o Brasil atualmente adota alguns mecanismos de incentivo a essas fontes de energia, tais como o Programa de Incentivos às Fontes Alternativas de Energia Elétrica (PROINFA), a realização de leilões de energias renováveis e o Plano Nacional da Agroenergia (EPE, 2007).

Quanto aos instrumentos de gestão desses planos, a maior parte dos mecanismos de investimento será efetivada por meio de linhas de financiamento disponibilizadas nos bancos oficiais. Isso fica muito evidente no caso da agricultura, em que o governo induz determinados setores a produzir cada vez mais, disponibilizando a maior fatia dos investimentos para a agricultura e pecuária comerciais, que geram divisas por meio de exportações (MAPA, 2011). O PNLT é efetivado principalmente por meio de investimentos diretos do governo e por financiamento público e privado. Da mesma forma que o PDE, o PNE também projeta a expansão energética do país, sendo propostos para sua efetivação a realização prioritária de leilões, podendo também o governo intervir por meio de subsídios e financiamentos para fontes energéticas específicas, a exemplo do PROINFA.

Os planos de desenvolvimento expostos propõem viabilizar suas ações prioritariamente por meio de instrumentos de mercado, sendo os instrumentos de comando e controle pouco representativos nesses setores, com exceção da infraestrutura de transporte, que depende de investimentos públicos.

\section{Consistências e contradições da estratégia governamental para as mudanças climáticas}

Nesta seção são apresentados os resultados da análise realizada. Busca-se aqui explorar as principais 
ações propostas para cada setor (florestas, agropecuária, energia e transportes) com relação às dimensões da sustentabilidade, no sentido de verificar as aproximações e distanciamentos na proposta do governo federal para a questão climática. Cada um dos aspectos definidos na metodologia é analisado separadamente nas próximas subseções, sendo apresentada uma tabela síntese ao final desta.

\subsection{Emissões de gases de efeito estufa e con- servação de florestas (aspectos 1 e 2)}

A PNMC, como uma política-quadro do Brasil, define que todos os planos setoriais de clima devem buscar o objetivo de redução das emissões projetadas de GEE, principalmente aquelas advindas do desmatamento, que representavam $58 \%$ das emissões totais do país até 2005. Por isso, as ações mais incisivas da PNMC foram focadas nessa finalidade, com o PPCDAm, o PPCerrado, o Plano ABC e o próprio Fundo Clima. Há instrumentos que indicam um caminho de redução do desmatamento, com concomitante redução das emissões de GEE, principalmente no caso do PPCDAm e do PPCerrado. A estimativa de emissões mais recente realizada pelo governo federal confirma que assim se deu, pois, em 2012, a participação do desmatamento na emissão total do país foi reduzida para apenas 15\% (MCTI, 2014).

As emissões totais de GEE no Brasil aumentaram $57,8 \%$ no período entre 1990 e 2005 , passando de 1,38 $\mathrm{Gt} \mathrm{CO}_{2} \mathrm{eq}^{3}$ para 2,19 Gt CO eq (MCTI, 2010). Todavia, no período entre 2005 e 2012, houve redução de cerca de $40 \%$ nas emissões totais, regredindo para $1,2 \mathrm{Gt} \mathrm{CO}_{2}$ eq, sendo resultado da redução dos índices de desmatamento na Amazônia (MCTI, 2014). Dessa forma, a meta de redução de emissões proposta pelo Brasil já teria sido alcançada em razão de uma combinação entre o baixo crescimento econômico dos últimos anos, muito abaixo da média de crescimento usada como premissa na PNMC (5\%), e o sucesso na redução das emissões derivadas do desmatamento da Amazônia.
Com essa queda na participação das emissões do desmatamento na Amazônia, a participação relativa do setor de energia dentro da matriz de emissões do país tende a aumentar cada vez mais, fazendo que o PDE seja muito tímido nas ações propostas. Em 2010, a participação do setor de energia nas emissões totais era de 19\%, aumentando, em 2012, para 37\% (MCTI, 2014).

O PDE é o único plano que, em seu conteúdo, se mostrou refratário a ações mais efetivas que contribuam com reduções nas emissões de GEE dentro da PNMC. Isso é evidenciado, em parte, pela importância que ganhou a expansão da produção de petróleo nos campos do pré-sal, pela não definição de marcos claros no tratamento das fontes renováveis de energia, com exceção da biomassa e hidroeletricidade, além do tratamento limitado da conservação de energia. Outra limitação do PDE e da meta de redução de emissões proposta na PNMC é que a segunda foi ajustada ao primeiro, ou seja, o PDE já existia, sendo a meta formulada em cima do que se podia fazer dentro de um cenário conservador (Business as usual) de expansão da oferta de energia. Além disso, como as concessões no setor se dão por meio de leilões, sendo utilizado o critério da menor tarifa por unidade de energia gerada para se definir o vencedor, somente as fontes de energia tradicionais são viabilizadas sem o estímulo de subsídios governamentais. Esse critério desfavorece a migração para tecnologias menos intensivas em GEE, que tendem a ser menos competitivas do ponto de vista econômico, dada a menor escala de produção, mas que poderiam trazer ganhos ambientais.

Vianna et al. (2009) observam que, além de contemplar um planejamento da geração que não altera a rota de desenvolvimento tecnológico para o setor de energia, há um equívoco governamental ao subsidiar a utilização de carvão, no Sul do país, e de térmicas a óleo combustível, no Norte, na forma de encargos setoriais pagos na conta de luz. Esse fato evidencia a falta de coerência do governo federal em inserir a mudança do clima no planejamento do setor energético.

Dos três planos de desenvolvimento analisados e das alterações realizadas no Código Florestal, somente o

${ }^{3}$ Giga tonelada de dióxido de carbono equivalente. 
PAP contempla ações que buscam reduzir as emissões de GEE e o desmatamento. Os outros planos, pelo contrário, indicam que podem contribuir significativamente com o aumento das emissões de GEE e/ou com o aumento das taxas de desmatamento, como é o caso das alterações no Código Florestal, o PNE 2030 e o PNLT.

Segundo Soares-Filho et al. (2014), o novo Código Florestal contribuirá para a diminuição em 58\% das áreas que deveriam ser reflorestadas em função de terem sido desmatadas ilegalmente pelas regras do Código Florestal anterior, mas que foram anistiadas com a aprovação da nova lei: de 50 milhões de hectares para 21 milhões de hectares, o que inclui áreas de reserva legal e proteção permanente. Além disso, a nova lei permite o desmatamento legal de mais 88 milhões de hectares, que anteriormente eram protegidas.

O PAP incorpora entre suas ações a integralidade do Programa $\mathrm{ABC}$, que é o plano setorial de mitigação e adaptação às mudanças climáticas da agricultura. Todavia a destinação de recursos federais para esse setor é majoritariamente alocada na agricultura e pecuária comerciais de grande escala, que fomentam a monocultura e a produção de gado bovino extensivamente. Em 2010, por exemplo, a lotação média de cabeças de gado por hectare no país estava em torno de 1,14 , indicando um uso muito extensivo do território. Dessa forma, as áreas de pastagens ocupam cerca de $74 \%$ das áreas destinadas à agropecuária no país (Sparovek et al., 2011).

Assim, predominam no país a agricultura monocultora de larga escala e a pecuária extensiva de gado bovino (IPEA, 2011), as quais se configuram em importantes vetores de desmatamento, principalmente a pecuária (Margulis, 2003). Essas atividades econômicas recebem ampla cobertura e incentivo do governo federal, em que pesem suas contradições ecológicas, sociais, e até mesmo econômicas, visto que em longo prazo a degradação ambiental desses ecossistemas pode comprometer sua rentabilidade.

Outra questão que pode ter repercussão sobre as áreas de florestas e que também está contemplada no PAP, é a expansão da produção de biocombustíveis. Nesse caso, há uma nítida interseção desse plano com estratégias energéticas desenhadas no PDE e o PNE.

O PNE estende no tempo o mesmo planejamento contemplado no PDE, que se baseia, eminentemente, na expansão das fontes tradicionais de energia e na carência do tratamento dispensado à economia de energia.

Em princípio, a expansão da produção de cana-de-açúcar não ameaçaria áreas de florestas, segundo estudo realizado pela Embrapa (Manzatto et al., 2009). Esse estudo mostra que o país dispõe de cerca de 65 milhões de hectares de áreas aptas à expansão dessa cultura. Entretanto seriam necessários avanços no zoneamento ecológico econômico e na regularização fundiária e ambiental de diversas regiões do país, além de fiscalização, pois, por mais que na visão do conjunto do território nacional haveria espaço para a expansão da cana-de-açúcar, regionalmente poderia haver competição com outros usos do solo, como áreas de florestas e produção de alimentos. Nesse sentido, não se pode afirmar que a expansão da produção de cana-de-açúcar não implicará pressão sobre áreas de florestas, sobretudo em um cenário de aumento da exportação do etanol.

O etanol apresenta duas facetas, que estão inscritas nos planos analisados neste trabalho. Por um lado, o etanol representa um grande avanço tecnológico e uma possibilidade real de contribuição para a transição para um modo de produção menos intensivo em carbono, sendo parte de um portfólio de novas tecnologias que contribuem com a mitigação das mudanças climáticas. Por outro, caso o Estado deixe seu desenvolvimento nas mãos do mercado e sem medidas de ordenamento territorial, ele pode representar uma ameaça para outros usos do solo no país, especialmente áreas de floresta e de produção de alimentos. Ademais, em que pesem as vantagens dessa tecnologia, o que se observa hoje é que o investimento na produção de cana-de-açúcar segue mais uma lógica produtivista do que a inserção de tal alternativa dentro de uma estratégia mais profunda de reversão da crise climática. Os subsídios federais dados à gasolina nos últimos anos, que contribuíram para menor competitividade do etanol, evidenciam a inexistência de uma política integrada de redução das emissões de GEE no país.

Outro tema relacionado ao desmatamento nos biomas brasileiros é a expansão dos grandes projetos de investimento, principalmente na Amazônia, uma das últimas fronteiras nacionais para a produção de hidroeletricidade e de minérios, entre outros. Nesse 
aspecto, o PDE indica como uma de suas principais ações de mitigação a expansão da produção de energia hidroelétrica na Amazônia. Por um lado, essa fonte pode contribuir com a manutenção da proporção de fontes renováveis na matriz energética, em contraposição com a instalação de termelétricas. Por outro, os impactos no território desses grandes empreendimentos, ainda mais na Amazônia, são cada vez mais contestados por causarem modificações socioambientais profundas em diversas regiões do bioma. O PNLT, adicionalmente, também projeta o aumento da malha rodoviária para esse bioma, além de ferrovias, como forma de viabilizar o escoamento da produção dessa região até os grandes centros consumidores, potencializando ainda mais as possibilidades de desmatamento.

Ainda que alguns avanços tenham sido feitos nas últimas décadas no setor de transportes, como no caso da expansão da produção de etanol e biodiesel e o aumento da frota de veículos bicombustíveis, esse setor ainda carece de uma política de infraestrutura que considere as mudanças climáticas como vetor de seu planejamento. A agenda nesse setor deveria passar pela redução do uso de estradas e rodovias e aumento do uso de ferrovias, navegação por rios e de cabotagem e melhoria dos sistemas públicos de transportes, com aumento da cobertura por metrôs e trens urbanos, além de melhor regulação e planejamento de longo prazo (Vianna et al., 2009).

A agenda do setor de transportes, ao contrário do que indicam os planos do governo federal, deveria ser condizente com a agenda do desmatamento zero, principalmente na Amazônia, pois o modelo rodoviário brasileiro impõe uma ameaça para esse bioma, devido à relação direta entre a expansão da malha rodoviária e o desmatamento (Vianna et al., 2009). Esse é um exemplo, entre outros, em que a integração entre políticas de desenvolvimento e os planos setoriais de mudanças climáticas torna-se fundamental.

No caso do controle do desmatamento da Amazônia, Abramovay (2010) elenca quatro fatores que contribuíram para a queda nas taxas de desmatamento nesse bioma. Em primeiro lugar está a forte ação coordenada da Polícia Federal com as agências do Ministério do Meio Ambiente nas gestões dos Ministros Marina Silva e Carlos Minc. O segundo fator reside na regulamenta- ção de algumas leis de restrição de crédito por parte de bancos a proprietários de áreas irregulares em termos ambientais ou propriedades não legalizadas. O terceiro fator agrupa a expansão das unidades de conservação e a demarcação de terras indígenas. O último fator está relacionado ao estabelecimento de instâncias de negociação formadas por distintos atores de setores cruciais, como a soja, os biocombustíveis e a pecuária. Isso está muito ligado à ação de ONGs que denunciam e divulgam informações sobre práticas empresariais que degradam o meio ambiente, obtendo resultados significativos, como no caso da moratória da soja e as negociações em torno da pecuária sustentável, modificando, em muitos casos, a conduta dos atores locais.

Esses fatores são importantes, agregados à definição das metas de redução das emissões de GEE em 2009, mas insuficientes para caracterizar uma estratégia de desenvolvimento sustentável para a região (Abramovay, 2010).

\subsection{A questão social: geração de emprego e renda e desigualdade social (aspectos 3 e 4)}

O tema da diminuição da desigualdade social é tratado tanto na PNMC como nos planos setoriais de clima, no máximo, como objetivo geral, com exceção do PPCDAm. Nesse plano há um conjunto de ações que buscam aliar a manutenção da floresta em pé, seu principal objetivo, com a geração de emprego e renda, o que concorre para a diminuição da desigualdade social na região. De forma geral, a desigualdade social ainda não figura entre os temas considerados importantes pelo governo quando se trata do enfrentamento da mudança climática. Mostra disso é a precariedade do tratamento dado à adaptação humana na PNMC até agora, que poderá ser revertida com a conclusão do Plano Nacional de Adaptação, que está em elaboração desde 2013 e deverá ser concluído em 2015.

Entre os planos de desenvolvimento, o único que contempla propostas definidas de geração de emprego e renda é o PAP, ainda que por meio de critérios de investimento. O PNE discorre sobre esse tema de forma genérica, pois projeta a expansão do setor e dos postos de trabalho que podem potencialmente surgir caso as 
opções energéticas venham a ser viabilizadas. Já o PNLT não se pronuncia sobre esse tema diretamente. No caso das alterações propostas para o Código Florestal não há elementos ainda que possam indicar aumento ou diminuição na geração de emprego e renda.

Quanto a ações focadas na desigualdade social, nenhum plano de desenvolvimento analisado contempla esse aspecto com propostas definidas e que visem de alguma maneira contribuir com sua redução.

Observa-se que o debate sobre mudanças climáticas é muito dominado pela abordagem dos aspectos físico-naturais e econômicos, restando pouca atenção para as questões sociais. A política do governo para a mudança do clima teria que ir mais a fundo naquilo que, por enquanto, está colocado apenas de forma retórica, quando os documentos reconhecem que os impactos das mudanças climáticas são diferenciados e que dependem da condição social dos afetados, faltando um estudo diagnóstico para se extrair consequências desta constatação e traçar ações concretas. Sem o tratamento da questão social, particularmente das desigualdades entre países e regiões do planeta e entre as diferentes classes sociais, não há uma transição possível, pois, para que seja viável abandonar a trajetória global de aumento das emissões de GEE, será preciso repensar as relações entre as sociedades e as classes, já que as emissões excessivas dos ricos de todo o planeta, e dos países ricos como um todo, não podem prevalecer sobre a manutenção da pobreza em muitas regiões. Isso vale também para a questão das desigualdades regionais e de classe dentro de cada país.

A redução das desigualdades entre classes sociais, regiões e países é condição necessária para o enfrentamento da mudança do clima, pois, conforme demonstra Pacala (2007), 7\% da população mundial mais rica emitem metade dos GEE lançados na atmosfera. Essas pessoas são as que consomem a maior parte do que a sociedade humana é capaz de produzir em termos materiais, usufruindo, portanto, de um padrão de vida que lhes garante, além de conforto material, maior resiliência perante os impactos das mudanças climáticas, mas também são elas as principais responsáveis pela mudança do clima, que causa impactos generalizados sobre o planeta. Assim, a afluência de determinados grupos acaba sendo responsável por impactos negativos, que são globais e se distribuem distintamente pelos territórios, afetando principalmente as populações mais vulneráveis, que são as mais pobres. Esse argumento é a base das noções de "(in)justiça ambiental” e "(in)justiça climática” (Acselrad et al., 2009; Milanez \& Fonseca, 2011).

Nesse sentido, Abramovay (2010) adverte que reduzir a desigualdade com responsabilidade ambiental passa pela redução do padrão de consumo dos ricos e não pela sua generalização, já que os limites ecossistêmicos para o crescimento da economia a fariam impossível.

\subsection{A componente adaptação (aspecto 5)}

A PNMC e os planos setoriais de clima não internalizaram até agora a adaptação como uma componente importante de enfrentamento à mudança do clima. Somente o Fundo Clima e o Plano ABC apresentam algumas ações específicas para a adaptação, por exemplo, a qualificação de profissionais em mudanças climáticas, a pesquisa em recursos genéticos e adaptação de sistemas agrícolas, a adoção de tecnologias que reduzam a vulnerabilidade das unidades e sistemas produtivos e o desenvolvimento de sistemas de alerta climático.

Como dito anteriormente, está em fase de elaboração o Plano Nacional de Adaptação, que pretende agrupar todos os esforços do país nesse tema. Sua finalização está prevista para 2015.

O único plano de desenvolvimento analisado que aborda o tema adaptação é o PAP, já que incorpora o Plano ABC entre suas ações. Os outros planos não tratam desta componente. Cabe ressaltar que o PNLT e o PNE foram elaborados antes de 2009, sendo que a introdução do tema mudança do clima nas políticas públicas ocorreu de forma mais organizada a partir daquele ano.

Por outro lado, a não consideração da problemática das mudanças climáticas nas discussões que ocorreram no Congresso Nacional para definir o novo Código Florestal cria um ambiente que pode induzir a um aumento do desmatamento no país e um desincentivo às recomposições florestais (Soares-Filho et al., 2014). Isso por si só pode contribuir para a diminuição da capacidade de adaptação de diversos sistemas naturais e sociais, visto que a redução de áreas de florestas pode comprometer a 
permanência de espécies biológicas nesses ambientes, bem como a manutenção de atividades econômicas que dependem de recursos das florestas para sua reprodução (Silva et al., 2011). Entre essas está a desregulação do ciclo hidrológico, que pode induzir situações de escassez hídrica e aumento de enchentes, agravando situações de vulnerabilidade humana.

A adaptação pode ser tratada com diversos enfoques, desde a da infraestrutura e da agricultura a eventos extremos ou modificações de longo prazo no sistema climático, passando pela adaptação dos ecossistemas até a de populações em situações de vulnerabilidade (IPCC, 2012). Nenhum desses enfoques recebe tratamento mais detalhado na política de clima do Brasil, evidenciando a precariedade da abordagem dada ao tema até este momento.

As vulnerabilidades socioambientais são resultantes, em última instância, da dinâmica do modelo de desenvolvimento, destacando-se também a própria precariedade do Estado em tratar esses temas, principalmente nos países em desenvolvimento. A realidade desses países, como o Brasil, é marcada pelo baixo nível de renda da maioria da população, pela dificuldade no acesso à moradia, principalmente nas cidades, que cresceram demasiadamente nas últimas décadas, pela deficiência de condições sanitárias (acesso à água potável e tratamento de esgoto) para grande parte da população, pelo acesso inadequado a serviços de saúde e educação entre outros (Abramovay, 2010). Esses fatores fazem que as populações mais pobres sejam as mais vulneráveis e menos resilientes nas situações frequentes de eventos climáticos extremos, como as chuvas que assolaram a região serrana do Rio de Janeiro em 2011. A protelação de ações estruturantes para esses grupos somente contribuirá para a redução da capacidade de resiliência, que já é pequena.

\subsection{Crescimento econômico (aspecto 6)}

A PNMC e os Planos setoriais de clima buscam reorientar a atividade econômica do país por meio da introdução de práticas que possibilitem a redução das emissões de GEE projetadas para 2020. O conjunto de planos que compõe a PNMC não propõe grandes alterações em processos correntes nos setores em que impactam, a não ser no caso do desmatamento (PPCDAm e PPCerrado), no qual são propostas medidas de comando e controle para coibir os desmatamentos ilegais, ao mesmo tempo que objetiva o fomento de atividades econômicas que valorizem a floresta em pé. O Plano ABC busca ampliar o uso de técnicas que já são conhecidas, mas que ainda não têm escala na agricultura brasileira. Já o PDE tem o objetivo de manter a proporção entre energias renováveis e não renováveis na matriz energética até 2020 , não alterando a matriz de produção de energia no país, senão o contrário, no afã de prover a demanda de energia, perde qualidade em termos de emissão de GEE.

Já os planos de desenvolvimento analisados são a base de intervenção do Estado em setores específicos e que buscam concretizar ou potencializar o crescimento econômico do país no curto, médio e longo prazo. Esses planos se estruturam para que, dentro de uma visão de competitividade internacional, o Brasil consiga atender a demanda interna pelos diversos produtos alimentares e industriais e também criar as condições para que outros setores econômicos exportadores consigam produzir e comercializar os produtos nacionais, ou mesmo atrair novos investimentos estrangeiros.

A PNMC foi elaborada considerando a projeção de emissão de GEE para 2020 baseada no cenário de crescimento da economia brasileira de cerca de $5 \%$ ao ano. Ou seja, não foi estabelecido um teto de emissão para o Brasil com base em um ano de referência que pudesse balizar os esforços de mitigação do país, mas foi feita uma projeção baseada em uma expectativa de expansão da economia. Essa projeção sobre-estimou as emissões futuras do país, sendo assim um esforço irreal de mitigação, já que o compromisso principal do país é com o crescimento econômico per se, desconsiderando uma real contribuição do país com a mitigação das mudanças climáticas.

Essa condução da política climática brasileira ainda prioriza o princípio das "responsabilidades comuns, porém diferenciadas", que norteou os fundamentos da Convenção Quadro das Nações Unidas sobre Mudança do Clima (CQNUMC), segundo a qual os países ricos são aqueles que deveriam contribuir mais para mitigar o aquecimento global por serem historicamente os principais responsáveis por esse fenômeno. Os países em desenvolvimento insistem na prerrogativa de crescer economicamente até que se alcance o mesmo nível de 
afluência dos países ricos. Todavia esse argumento tem encontrado alguns limites nas últimas negociações das partes da CQNUMC, uma vez que os países em desenvolvimento, entre eles o Brasil, já apresentam níveis de emissão de GEE maiores que os países ricos (Viola et al., 2013). Atualmente, a China é o maior emissor de GEE do planeta (Motta et al., 2011).

Esse argumento revela, por um lado, o mesmo paradigma de manutenção do crescimento econômico tradicional como único meio que se concebe para atingir o desenvolvimento do país. O que se convencionou chamar de desenvolvimento se reduz ou se confunde com crescimento econômico (Leff, 2006). Por outro, desvela-se também a tensão existente entre meio ambiente e desenvolvimento, pois se receia que uma significativa redução nas emissões levaria à redução da taxa de expansão da economia brasileira, inviabilizando o projeto de país que se inspira no modelo de desenvolvimento dos países ricos do Norte. Em grande parte é esse mesmo padrão de desenvolvimento que gerou e agravou o aquecimento do clima do planeta (Leff, 2006; Victor et al., 2014).

Para Vianna et al. (2009) o modo de produção capitalista tem a necessidade constante de renovação de sua base técnica, sendo que a superação das energias que emitem GEE tem o potencial de se tornar a próxima onda de inovação, favorecendo uma saída para a crise ambiental mais condizente com os ideais da sustentabilidade, ou, pelo menos, de uma economia menos emissora de GEE. Eles salientam também que seria necessário abandonar o paradigma de desenvolvimento industrial dos séculos XIX e XX, como forma de concretizar um novo paradigma regional e de baixo teor de carbono, que conduziria ao aumento da qualidade da democracia e do bem- estar da sociedade brasileira.

\subsection{As dimensões da sustentabilidade privilegiadas nos instrumentos de política pública analisados}

Nesta seção, tendo como base as análises realizadas nas seções anteriores, são evidenciadas as dimensões da sustentabilidade privilegiadas nas políticas públicas relativas à mudança climática. Apresenta-se, na Tabela 4, a seguir, o resumo dessas análises por meio da atribuição de valores quantitativos aos diferentes aspectos considerados em cada política ou instrumento de política.

Os instrumentos de política pública analisados neste artigo privilegiam de maneira desigual as dimensões da sustentabilidade. Em alguns, a componente ecológica (aspectos 1 e 2) recebe maior ênfase, ao passo que em outros a dimensão econômica (aspecto 6) predomina, sendo a ecológica usada como meio para se atingir fins econômicos. Em nenhum desses instrumentos a dimensão social (aspectos 3 e 4) predomina sobre as demais, podendo ser mais ou menos considerada, dependendo do caso. $\mathrm{O}$ aspecto adaptação (5) é precariamente tratado no conjunto da política de clima, devendo esse quadro ser revertido quando da conclusão do Plano Nacional de Adaptação, em 2015.

A PNMC, como uma política-quadro de mudanças climáticas, privilegia a dimensão ecológica sobre as demais (atribuição de valor 2 aos aspectos 1 e 2; valor 0 para o aspecto 6), já que seu objetivo principal é mitigar as emissões de GEE do país. No PPCDAm e no PPCerrado, a dimensão ecológica da mudança climática também predomina (valor 2 nos aspectos $1 \mathrm{e}$ 2), estando em segundo lugar a dimensão social (valor 2 nos aspectos 3 e 4 no PPCDAM, e valores 2 e 1 para os mesmos aspectos no PPCerrado). Seus instrumentos de gestão ambiental são fortemente ancorados em ações de comando e controle que têm como objetivo principal conter o desmatamento nesses biomas, com concomitante redução das emissões de GEE, por meio da criação de áreas protegidas, fiscalização, regularização fundiária, além da geração de emprego e renda, e, no caso do PPCDAm, redução da desigualdade social. Há também instrumentos de mercado, que buscam viabilizar a produção que contemple a redução das taxas de desmatamento e de emissões de GEE. Esses planos têm um viés mais preservacionista do que os outros, pois buscam definir limites territoriais para a expansão das atividades econômicas. 
TABELA 4 - Resultado da análise das políticas públicas com base nos aspectos e respectivas escalas de variação (de acordo com a tabela 1).

\begin{tabular}{|c|c|c|c|c|c|c|c|c|c|c|}
\hline Aspectos & PNMC & PPCDAm & PPCerrado & $\begin{array}{c}\text { Plano } \\
\text { ABC }\end{array}$ & $\begin{array}{l}\text { PDE } \\
2020\end{array}$ & $\begin{array}{l}\text { Fundo } \\
\text { Clima }\end{array}$ & PAP & PNLT & $\begin{array}{l}\text { PNE } \\
2030\end{array}$ & $\begin{array}{c}\text { Novo } \\
\text { Código } \\
\text { Florestal }\end{array}$ \\
\hline $\begin{array}{l}\text { 1. Emissões } \\
\text { de GEE }\end{array}$ & 2 & 2 & 2 & 2 & -1 & 2 & 2 & -1 & -1 & -1 \\
\hline $\begin{array}{l}\text { 2. Conservação } \\
\text { de florestas }\end{array}$ & 2 & 2 & 2 & 2 & 0 & 2 & 2 & -1 & 0 & -1 \\
\hline $\begin{array}{l}\text { 3. Geração de } \\
\text { emprego e renda }\end{array}$ & 0 & 2 & 2 & 2 & 2 & 1 & 2 & 0 & 1 & 0 \\
\hline $\begin{array}{l}\text { 4. Desigualdade } \\
\text { social }\end{array}$ & 0 & 2 & 1 & 1 & 0 & 0 & 0 & 0 & 0 & 0 \\
\hline 5. Adaptação & 0 & 0 & 0 & 2 & 0 & 2 & 1 & 0 & 0 & -1 \\
\hline $\begin{array}{l}\text { 6. Crescimento } \\
\text { econômico }\end{array}$ & 0 & 0 & 0 & 2 & 2 & 0 & 2 & 2 & 2 & 1 \\
\hline
\end{tabular}

No Plano ABC prevalece a dimensão econômica da mudança climática (valor 2 no aspecto 6), dentro de uma visão de oportunidade, já que o setor compete no mercado internacional. Assim, busca-se reduzir as emissões de GEE por meio de instrumentos de mercado, predominantemente, financiamentos públicos (valor 2 no aspecto 1). Para que sejam viáveis essas técnicas (integração Lavoura-Pecuária-Floresta, plantio direto na palha, fixação biológica de nitrogênio entre outras), elas devem permitir que os proprietários rurais tenham retorno financeiro do investimento feito. Nesse caso, a dimensão ecológica é considerada, mas somente se ela propiciar retorno do capital investido. Raciocínio semelhante pode ser feito para a conservação de florestas e a questão social (valor 2 para os aspectos 2 e 3, e valor 1 no aspecto 4$)$.

Já o PDE-2020 trata predominantemente da dimensão econômica (valor 2 no aspecto 6), pois prioriza o abastecimento de energia para a economia, acima de tudo, considerando a geração de emprego e renda tão somente como um meio para se alcançar esse objetivo (valor 2 no aspecto 3). A dimensão ecológica é resgatada em alguns momentos como ponte para se atingir a dimensão econômica. São enfatizadas as oportunidades que a mudança climática traz em termos da expansão de fontes de energia ligadas à bioenergia, como o etanol e o biodiesel. Todavia, no agregado, o PDE indica aumento futuro nas emissões de GEE, principalmente como resultado da exploração do pré-sal (valor -1, aspecto 1). Esse plano propõe majoritariamente instrumentos de mercado como forma de interferir no comportamento de agentes privados quanto à expansão das fontes de energia no país.

O Fundo Clima define grandes linhas de financiamento que propõe operacionalizar a PNMC; assim, privilegia a dimensão ecológica (valor 2 para os aspectos 1 e 2), incluindo também a adaptação (valor 2, aspecto 5), e trata secundariamente a dimensão social (valores 1 e 0 para os aspectos 3 e 4). Seus objetivos iniciais visavam, principalmente, contemplar a mitigação das emissões de GEE.

Os planos de desenvolvimento analisados privilegiam predominantemente, e como é de se esperar, a 
dimensão econômica (valor 2 para o aspecto 6), pois são instrumentos setoriais do governo federal que buscam criar as condições básicas para o crescimento econômico do país. O PNE 2030 e o PNLT focam suas ações na expansão do setor energético e de logística e transportes, respectivamente, com uma precária ou inexistente consideração das dimensões ecológica e social (valores -1 e 0 para os aspectos 1 a 5). Única exceção com relação à geração de emprego é o PNE, que, tal como o PDE, objetiva esse aspecto como meio para a expansão da matriz energética nacional (valor 1, aspecto 3). Ainda que marginalmente, o PAP já incorpora ações que buscam reduzir as emissões de GEE e o desmatamento, além de fomentar a adaptação na agricultura por meio do Programa ABC (valor 2 para os aspectos 1, 2 e 5). A dimensão ecológica é considerada nesse plano, mas dentro da perspectiva de competitividade da agricultura nacional no mercado global. Sendo assim, é considerada como meio para se atingir a sustentabilidade econômica.

Por fim, o Código Florestal, enquanto política ambiental, busca definir os limites territoriais nos quais as atividades econômicas podem interferir na dimensão ecológica, por meio da definição de áreas de proteção permanente e reservas legais, entre outros instrumentos. Essa política tem como fundamento a proteção ambiental, portanto, privilegia de forma geral a dimensão ecológica sobre as demais. No entanto, as alterações propostas buscam reduzir as áreas de proteção ambiental (valor -1 para os aspectos 1,2 e 5) e flexibilizar a aplicação da lei como forma de permitir maior uso do território ou a consolidação do uso já feito pelas atividades econômicas (valor 1, aspecto 6). A dimensão social recebe pouca ou nenhuma atenção nessa lei (valor 0, aspectos 3 e 4). Em que pese o fato dessa política privilegiar a dimensão ecológica, as alterações propostas buscam dar maior ênfase à dimensão econômica da sustentabilidade.

\section{Considerações finais}

A visão subjacente a todas as políticas e planos analisados neste artigo coloca a competitividade da economia brasileira acima de qualquer outro objetivo. Logo, o crescimento econômico tem um status de prioridade, com algumas exceções, como no caso do desmatamento. Ainda que os planos climáticos não busquem fomentar o crescimento econômico de forma deliberada, eles procuram reorientar esse crescimento.

A PNMC e seus planos apresentam outras consistências importantes: buscam a redução das emissões de GEE no país, mesmo que sejam questionados os valores dessa redução; procuram, como um dos principais objetivos do Brasil nesse tema, reduzir as taxas de desmatamento nos biomas de floresta; no caso da agricultura, o Plano ABC propõe a introdução de importantes técnicas que potencialmente levarão à redução das emissões no campo, bem como ao aumento das áreas de florestas plantadas, tendo uma forte interseção com o PPCDAm e o PPCerrado. Por fim, o PDE propõe a expansão da produção de biocombustíveis e a construção de plantas de hidroeletricidade, como medidas de mitigação. Estes últimos planos podem ter repercussões contraditórias, principalmente sobre a floresta amazônica.

Quando confrontadas com as políticas de desenvolvimento, as contradições dessas com as políticas climáticas ficam mais evidentes. O caso do pré-sal é o mais importante, pois é um dos componentes mais fortes presentes no planejamento do setor energético tanto no PDE quanto no PNE 2030. Ademais, o PAP, ainda que incorpore o Plano ABC entre suas ações, busca fomentar majoritariamente a monocultura agrícola e a pecuária extensiva, que são ineficientes em termos de uso do território, e com repercussões negativas em seu contato com as regiões de floresta, além de serem grandes fontes de emissão de GEE. Também o PNLT, ainda que possa indicar maior investimento em ferrovias em detrimento de rodovias, não incorpora elementos de enfrentamento à mudança climática, além de não abordar temas fundamentais como a mobilidade urbana e o transporte público. Por fim, as alterações realizadas no Código Florestal podem repercutir negativamente sobre as áreas de floresta do país, potencializando as emissões e/ou reduzindo os estoques de dióxido de carbono na vegetação.

Cabe ressaltar que nos últimos anos o Brasil tem conseguido reduzir consideravelmente a desigualdade social por meio da geração de emprego e transferência de renda e recursos à população por meio de aumento dos salários e diversos benefícios e programas sociais. 
Isso tem sido alcançado em razão de um planejamento governamental que prioriza a expansão econômica como forma de viabilizar essa orientação de cunho mais social. Tais avanços sociais são, sem dúvida, importantes para o país. Contudo os padrões dominantes de produção e consumo, que têm permitido tais avanços, baseiam-se em processos de degradação ambiental mais acelerados e contundentes do que a ação de contenção derivada da aplicação da legislação ambiental vigente. Ficam patentes, nesse caso, as limitações que a abordagem das questões ambientais tem na sociedade de consumo atual.

As políticas climáticas que estão sendo estruturadas pelo governo federal são um primeiro movimento no sentido de contemplar de alguma maneira a agenda das mudanças climáticas, todavia ainda muito tímido e com limitações de operacionalização. Mais do que uma política ambiental, a PNMC deve ser considerada como um misto de política ambiental e de desenvolvimento,

\section{Referências}

Abramovay, R. Desenvolvimento sustentável: qual a estratégia para o Brasil? Novos Estudos, 87, 2010.

Acselrad, H.; Mello; C.; Bezerra, G. O que éjustiça ambiental. Rio de Janeiro: Garamond, 2009.

Brasil. Lei $n^{\circ} 12.187$, de 29 de dezembro de 2009. Institui a Política Nacional sobre Mudança do Clima e dá outras providências. Brasília: DOU, Seção Extra, p. 109, Coluna 2. 2009.

Brasil. Decreto $n^{\circ} 7.390$, de 09 de dezembro de 2010. Regulamenta os arts. $6^{\circ}, 11^{\circ}$ e $12^{\circ}$ da Lei n ${ }^{\circ} 12.187$, de 29 de dezembro de 2009, que institui a Política Nacional sobre Mudança do Clima, e dá outras providências. Brasília: DOU de 09 dez. 2010.

EPE - Empresa de Pesquisa Energética. Plano Nacional de Energia 2030. Ministério de Minas e Energia. Rio de Janeiro, 2007.

EPE - Empresa de Pesquisa Energética. Plano Decenal de Expansão de Energia 2020. Ministério de Minas e Energia. Brasília, 2011.

Giddens, A. A política da mudança climática. Rio de Janeiro: Zahar, 2010.

IPCC - Intergovernmental Panel on Climate Change. IPCC Special Report on Managing the Risks of Extreme Events ou uma política de desenvolvimento sustentável ainda em construção, pois irá demandar cada vez mais que setores da sociedade alterem seus padrões de produção e de consumo de forma a considerar as limitantes ecológicas (emissão de GEE) para o funcionamento da economia. Além disso, a política de clima do Brasil ainda não consegue integrar esforços no sentido de enfrentar a questão das desigualdades sociais, desconsiderando o fato de que o segmento mais rico da sociedade emite a maior parte das emissões de GEE e tem a capacidade de se adaptar mais facilmente aos impactos das mudanças climáticas do que o segmento mais pobre.

A grande questão que se coloca é se as demandas que a mudança do clima está impondo às sociedades repercutirão em ações que levem em conta conceitos como os de justiça ambiental e climática, indo além das fundamentais, mas insuficientes, soluções essencialmente tecnológicas. Isso dependerá, entre outros fatores, do grau de informação e organização da sociedade.

and Disasters to Advance Climate Change Adaptation (eds. Field, C.B., Barros, V., Stocker, T.F., Qin, D., Dokken, D., Ebi, K.L., Mastrandrea, M.D., Mach, K.J., Plattner, G.-K., Allen, S., Tignor, M., Midgley, P.M.). Cambridge University Press, Cambridge. 2012.

IPEA - Instituto de Pesquisas Econômicas Aplicadas. Código florestal: implicações do PL 1876/99 nas áreas de reserva legal. Comunicados do IPEA, n. 96, 2011.

Leff, E. Racionalidade ambiental: a reapropriação social da natureza. Tradução Luís Carlos Cabral. Rio de Janeiro: Civilização Brasileira, 2006. 555 p.

Manzatto, C. V.; Assad, E. D.; Bacca, J. F. M.; Zaroni, M. J.; Pereira, S. E. M. (Orgs.). Zoneamento agroecológico da cana-de-açúcar: expandir a produção, preservar a vida, garantir o futuro. Rio de Janeiro: Embrapa Solos, 2009.

MAPA - Ministério da Agricultura, Pecuária e Abastecimento. Plano Agrícola e Pecuário 2011-2012, Brasília: MAPA/SPA, 2011.

Margulis, S. Causas do desmatamento da Amazônia brasileira. Brasília: Banco Mundial, 1ª edição, 2003. 
MCTI - Ministério da Ciência, Tecnologia e Inovação. $2^{a}$ comunicação Nacional do Brasil à Convenção-Quadro das Nações Unidas sobre Mudança do Clima. Brasília, 2010.

MCTI - Ministério da Ciência, Tecnologia e Inovação. Estimativas Anuais de Emissões de Gases de Efeito Estufa no Brasil - $2^{a}$ Edição. Brasília, 2014.

Milanez, B.; Fonseca, I. F. O discurso da justiça climática no contexto brasileiro: possibilidades e perspectivas. In: Motta, R. S.; Hargrave, J.; Luedemann, G.; Gutierres, M. B. S (Eds.). Mudança do Clima no Brasil: aspectos econômicos, sociais e regulatórios. Brasília, IPEA, 2011.

Motta, R. S.; Hargrave, J.; Luedemann, G. As metas do acordo de Copenhague e as decisões de Cancun. In: Motta, R.S.; Hargrave, J.; Luedemann, G.; Gutierres, M. B. S (Eds.). Mudança do Clima no Brasil: aspectos econômicos, sociais e regulatórios. Brasília, IPEA, 2011.

MT - Ministério dos Transportes. Plano Nacional de Logística e Transportes (Relatório Executivo). Ministério dos Transportes. 2009. Disponível em: <www.transportes.gov.br>. Acesso em: jul. 2014.

Pacala, S. Equitable solutions to greenhouse warming: on the distributions of wealth, emissions and responsability between nations. IIASA Conference, 2007. Disponível em: <http:// www.iiasa.ac.at/Admin/PUB/podcast/16pacala.pdf $>$. Acesso em: 12 out. 2012.

Pierri, N. El proceso histórico y teórico que conduce a la propuesta del desarrollo sustentable. In: Pierri, N.; Foladori, G. (Eds.). Sustentabilidad? Desacuerdos sobre el desarrollo sustentable. Montevideo: Trabajo y Capital, 2001.

Romeiro, V.; Parente, V. Regulação das mudanças climáticas no Brasil e o papel dos governos subnacionais. In: Motta, R.S.; Hargrave, J.; Luedemann, G.; Gutierres, M. B. S (Eds.). Mudança do Clima no Brasil: aspectos econômicos, sociais e regulatórios. Brasília, IPEA, 2011.

Sachs, I. Caminhos para o desenvolvimento sustentável. Rio de Janeiro: Garamond, 2008.
Silva, J. A. A.; Nobre, A. D.; Manzatto, C. V.; Joly, C. A.; Rodrigues, R. R.; Skorupa, L. A.; Nobre, C. A.; Ahrens, S.; May, P. H.; Sá, T. D. A.; Cunha, M. C.; Rech Filho, E. L. $O$ Código Florestal e a Ciência: contribuições para o diálogo. São Paulo: Sociedade Brasileira para o Progresso da Ciência, SBPC, Academia Brasileira de Ciências, ABC. 2011, 124p.

Soares-Filho, B.; Rajao, R.; Macedo, M.; Carneiro, A.; Costa, W.; Coe, M.; Rodrigues, H.; Alencar, A. Cracking Brazil's Forest Code. Science, 344 (6182), 363-364, 2014.

Sparovek, G.; Barreto, A. Klug, I.; Papp, L. Lino, J. A revisão do Código Florestal brasileiro. Novos Estudos, 89, 2011.

UNEP - United Nations Environmental Programme. Measuring Progress: Environmental Goals \& Gaps. United Nations Environment Programme (UNEP), Nairobi, 2012.

Vianna, S. B.; Veiga, J. E.; Abranches, S. A Sustentabilidade do Brasil. In: Giambiagi, F.; Barros, O. de (Org.). Brasil Pós-Crise: Agenda para a próxima década. Ed. Campos, 2009, p. 305-324.

Victor, D. G.; Zhou, D.; Ahmed, E. H. M ; Dadhich, P. K.; Oliver, J. G. J.; Rogner, H. H.; Sheikho, K.; Yamaguchi, M. Introductory Chapter. In: Edenhofer, O.; Pichs-Madruga, R.; Sokona, Y.; Farahani, E.; Kadner, S.; Seyboth, K.; Adler, A.; Baum, I.; Brunner, S.; Eickemeier, P; Kriemann, B.; Savolainen, J.; Schlömer, S.; Von Stechow, C.; Zwickel, T.; Minx, J. C. (Eds.). Climate Change 2014: Mitigation of Climate Change. Contribution of Working Group III to the $5^{\text {th }}$ Assessment Report of the IPCC. Cambridge University Press, Cambridge, United Kingdom and New York, NY, USA, 2014.

Viola, E.; Franchini, M.; Ribeiro, T. L. Sistema Internacional de Hegemonia Conservadora: Governança Global e Democracia na Era da Crise Climática. $1^{\mathrm{a}}$ ed. São Paulo: Anna Blume, 2013, 405p.

Vitousek, P. M.; Mooney, H. A.; Lubchenco, J.; Melillo, J. M. Human domination of earth's ecosystems. Science, 277(5325), 494-499, 1997. 